\title{
Detailed In Situ Hot Stage Transmission Electron Microscope Observations of the Localized Pinning of a Mobile Ferrite-Austenite Interface in a Fe-C-Mn Alloy by a Single Oxidic Particle
}

\author{
J. NUTTER, W.M. RAINFORTH, and S. VAN DER ZWAAG
}

\begin{abstract}
The current study reports the detailed analysis of an observation of the local pinning of a slowly moving austenite-ferrite interface by a single nanosized oxidic particle. The observations were made during an in situ cyclic partial phase transformation experiment on a Fe-0.1C-1.0Mn alloy close to the inversion stage at which the interface migrates at a rather low velocity. The low velocity allowed capturing the interface pinning effect over a period of no less than 16 seconds. From our observations, it was possible to follow the progression of the pinning effect from the initial stages all the way through to the release of the interface. The pinning force exerted by the individual particle having a diameter of $140 \mathrm{~nm}$ on the austenite-ferrite interface was estimated as $175 \mathrm{~nJ} \mathrm{~m} \mathrm{~m}^{-1}$, while the maximum pinning length was approximately $750 \mathrm{~nm}$ to either side of the particle, leading to an interface line tension of $170 \mathrm{~nJ} \mathrm{~m}^{-1}$. The observed pinning behavior is compared with the most relevant models in the literature.
\end{abstract}

https://doi.org/10.1007/s11661-020-05824-y

(c) The Author(s) 2020

\section{INTRODUCTION}

SECOND-PHASE particles can provide a significant local pinning force on moving grain boundaries and moving interfaces and this effect can be, and is being, used to control the final grain size in polycrystalline metals exposed to a thermal treatment. ${ }^{[1-4]}$ In microalloyed steels, carbide, nitride or carbonitride forming species, such as $\mathrm{Nb}$ or $\mathrm{Ti}$, are widely used to assist microstructural control during thermomechanical processing by arresting static recrystallisation of austenite at low temperatures and inhibiting austenite grain coarsening. ${ }^{[5-9]}$ A first theoretical analysis of the interaction of pre-existing (stationary) particles with migrating grain boundaries during recrystallization (i.e., conditions in which the same phase is present on both sides of the interface, but there is a large difference in dislocation density) was formulated by Zener and presented by Smith. ${ }^{[10-12]} \mathrm{He}$ argued that the inhibiting effect on migration arises from the reduction in interfacial energy

J. NUTTER and W. M. RAINFORTH are with the The Henry Royce Institute and Department of Material Science and Engineering, The University of Sheffield, Sir Robert Hadfield Building, Sheffield, S1 3JD, UK. Contact e-mail: j.nutter@sheffield.ac.uk. S. VAN DER ZWAAG is with the Faculty of Aerospace Engineering, Delft University of Technology, Kluyverweg 1, 2629 HS, Delft, The Netherlands.

Manuscript submitted January 21, 2020.

Article published online May 21, 2020 when the grain boundary contacts the particle. Given his explanation, similar considerations are expected to apply to the interaction of particles with interphase boundaries migrating under diffusional transformation conditions. However, in such a case where different phases exist on either side of the interface the driving force for interface motion generally is much higher than for recrystallization conditions and the effect may be less notable. ${ }^{[13]}$ Previous experimental studies of the $\delta$-ferrite-to-austenite and $\alpha$-ferrite-to-austenite transformations indicate that the transformation interfaces interact with particles in the parent phase ${ }^{[14,15]}$ and transformation kinetics were found to be retarded in a similar fashion to Zener pinning during grain growth. ${ }^{[4,14]}$ The interaction of oxide particles with grain boundaries can also reduce austenite grain growth at high temperatures $\left(1200{ }^{\circ} \mathrm{C}\right)$ in $\mathrm{Fe}-0.15 \mathrm{C}-1.0 \mathrm{Mn}-1.0 \mathrm{~N}$ steels deoxidized with $\mathrm{Ti}$ and $\mathrm{Zr}^{[16]}$ and improve stability of the microstructure in austenitic stainless steel heat treated at 1150 to $1250{ }^{\circ} \mathrm{C}$ for 100 to 1000 hours. ${ }^{[17]}$

While the pinning effect exerted by second-phase particles on grain boundaries and transformation interfaces has been studied extensively both experimentally and theoretically, ${ }^{[4,12,14-25]}$ only a single publication on TEM observation of interface pinning in an $\mathrm{Al}$ alloy ${ }^{[26]}$ could be found in literature. No such observations have been reported for diffusional phase transformations in conventional or modern construction steels, being the most important alloys in society. Multiple in situ TEM studies have been carried out to investigate boundary 
migration in steels (with pinning effects absent). Purdy ${ }^{[27]}$ used high-voltage electron microscopy to observe mobile austenite-ferrite interfaces in Fe-C-Mo alloys which possessed both smoothly curved (normal) interfaces which were responsive to temperature changes of as little as $3{ }^{\circ} \mathrm{C}$ and less mobile faceted (lateral) interfaces. Onink et al. ${ }^{[28]}$ used hot stage TEM to make kinetic measurements of the austenite-to-ferrite transformation in Fe-0.36 wt pet $\mathrm{C}$ and $\mathrm{Fe}-0.71$ wt pet $\mathrm{C}$ steels transformed between 707 and $767^{\circ} \mathrm{C}$. Interfaces displayed both the normal and lateral mode growth observed by Purdy, with measured migration rates of 10 to $1000 \mathrm{~nm} \mathrm{~s}^{-1}$. Du et al. ${ }^{[29]}$ studied the growth of austenite from a ferrite matrix in a $\mathrm{Fe}-24.9 \mathrm{Cr}-7.0$ Ni-3.1 Mo duplex stainless steel above $700{ }^{\circ} \mathrm{C}$, analyzing the dislocations emitted from the austenite lath tip during growth. Mompiou et al. ${ }^{[30]}$ studied martensite-austenite boundary migration in a Fe-20Ni-5.4Mn alloy between 400 and $600{ }^{\circ} \mathrm{C}$ observing interfacial dislocations in both normal and lateral mode interface migration. Nutter et al. ${ }^{[31]}$ performed cyclic partial phase transformation heat treatments between $790{ }^{\circ} \mathrm{C}$ and $840^{\circ} \mathrm{C}$ on a $\mathrm{Fe}-0.1 \mathrm{C}-0.5 \mathrm{Mn}$ steel, observing an evolving morphology in interface migrating in the normal mode and making kinetic measurements, maximum measured velocities during the austenite-to-ferrite transformation were 100 to $1000 \mathrm{nms}^{-1}$. Both Onink et al. and Nutter et al. found overall transformation kinetics that were consistent with calculation or bulk experiment. This absence of direct observations is not surprising given the inherently short interaction time of less than 2 seconds between an austenite-ferrite interface moving at a usual velocity exceeding $100 \mathrm{nms}^{-1[31]}$ and regular pinning particles with a typical diameter of 200 nm.

In the present study, which originated from its parent study on the austenite-ferrite interface velocity during cyclic partial phase transformations in a Fe-0.1C-1.0Mn model alloy for 2 nd and 4th generation automotive steels, the (absolute) austenite-ferrite interface velocity typically varies between $<10$ and $600 \mathrm{~nm} / \mathrm{s}$, depending on the (temperature) distance between the cooling-heating inversion points. ${ }^{[31]}$ Under such slowly moving interface conditions the pinning of the moving interface by a single (oxide) particle can be captured with sufficient spatial ( $20 \mathrm{~nm})$ and temporal (0.16 seconds) resolution in in situ TEM experiments at low magnification.

\section{EXPERIMENTAL METHODS}

The as-received material was a ternary Fe-C-Mn model alloy for automotive steels containing 0.095 wt pet carbon and $1.0 \mathrm{wt}$ pct manganese and 0.026 wt pet silicon and had been machined to $5 \mathrm{~mm} \times 10 \mathrm{~mm}$ cylindrical specimens suitable for dilatometry. The starting microstructure consisted primarily of equiaxed ferrite grains with a smaller fraction of bainitic ferrite also apparent. Specimens were prepared for hot stage TEM experiments by sectioning along the cylinder axis and mechanically thinning to approximately $100 \mu \mathrm{m}$.
$3 \mathrm{~mm}$ discs were punched out from this material and electropolished in a Struers TenuPol-5 electropolishing unit at $-45^{\circ} \mathrm{C}$ with a 5 pet perchloric acid, 35 pct 2-butoxyethanol, 60 pct methanol solution. Prior to insertion in the TEM specimens were examined to ensure that the central perforation had smooth edges and minimal etching artifacts or signs of oxidation of the surface.

Hot stage TEM experiments were carried out in a JEOL JEM 3010 UHR TEM operated at $300 \mathrm{kV}$, with a $\mathrm{LaB}_{6}$ filament. Video was recorded using the attached TVIPS camera with a $100 \mathrm{~ms}$ exposure time for individual frames. The hot stage was a GATAN model 628 single tilt heating holder with a Ta furnace and an attached model 628.09J water re-circulator which was switched on 20 minutes before the heat treatment began. Temperature control was carried out using a serial connection to a PC in which the temperature was adjusted according to a pre-selected routine programed using Python. The selected heat treatment, which is shown in Figure 1, was chosen to replicate a cyclic partial phase transformation (CPPT) experiment. ${ }^{\text {[32-34] }}$ This involves cycling the temperature between two temperature $T_{1}$ and $T_{2}$ both of which are within the $\alpha+\gamma$ two phase region. This protocol eliminates the effect of nucleation on the kinetics as the transformation progresses through the migration of already existing interfaces and further can be used to investigate the local chemistry at the interface. During CPPT experiments, the austenite-to-ferrite and ferrite-to-austenite transformations undergo two distinct transformation stages $^{[32]}$ - the "normal" (that is as expected from thermodynamic considerations) transformation and the "inverse" transformation which during which the transformation continues even though the $T_{1}$ (or $T_{2}$ ) temperature has been reached and heating (or cooling) of the specimen has begun. These two transformations are interspersed with a stagnant stage (occurring once on heating and once on cooling) during which the interface migrates only sluggishly. See Figure 1 for the complete thermal cycle and the (expanded) time-temperature domain during the observation reported here.

Other CPPT in situ TEM experiments using this composition were scrutinized for further examples of this pinning effect. However, although there were some cases (see supplementary video 2) where clear interaction between the interface and likely oxide particles could be observed, these were generally not suitable for similarly detailed measurements to be performed, due to a combination of higher interface velocity and difficulty in estimating particle size.

Post-heat treatment analysis was carried out using a JEOL JEM-F200 TEM operated at $200 \mathrm{kV}$, with a Cold FEG gun, and equipped with a GATAN OneView camera for imaging. Due to the use of a $100-\mu \mathrm{m}$-thick magnetic specimen, TEM-EDS analysis was carried out using spot size 7 with a $10 \mu \mathrm{m}$ condenser aperture. Under these conditions, the minimum FWHM of the beam is below $2 \mathrm{~nm}$. This analysis indicated that there were a number of oxide particles distributed throughout the thin foil with a size on the order of $200 \mathrm{~nm}$. Figure 2 shows a bright field TEM image of a typical particle of 


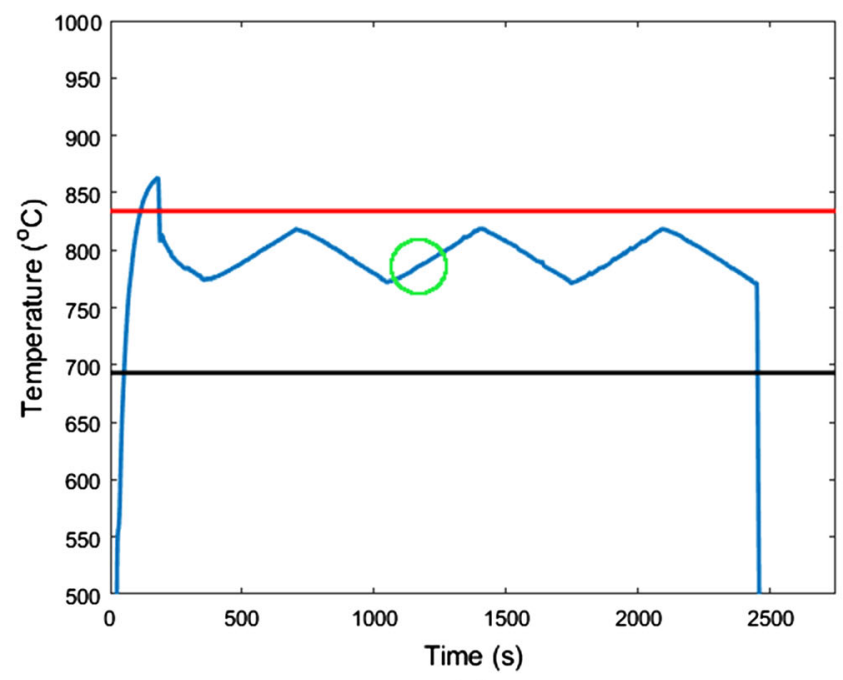

(a)

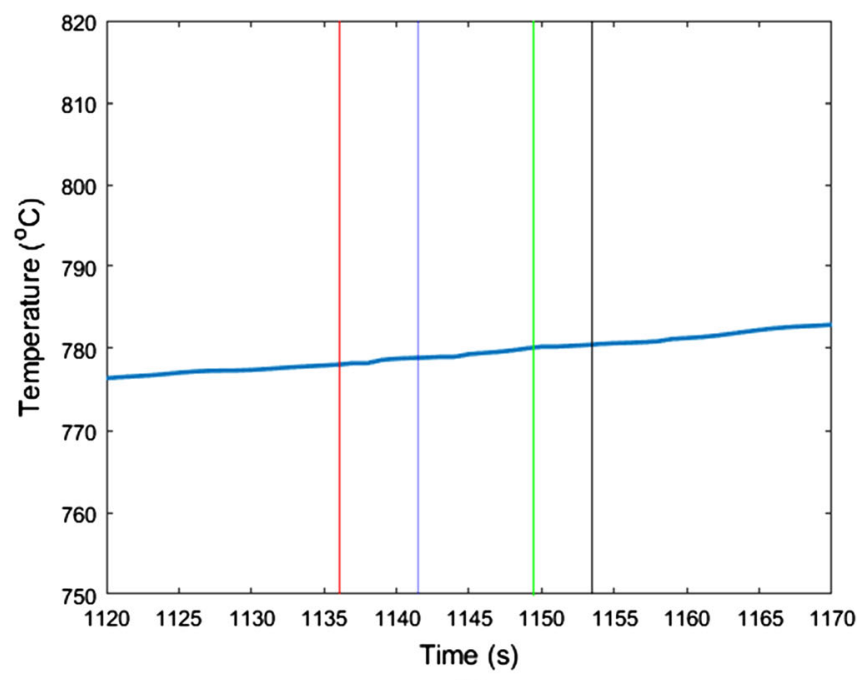

(b)

Fig. 1-(a) Graph of temperature against time showing the applied thermal treatment in the TEM, with the upper and lower temperature of the two phase region marked by the red and black lines, respectively. The (enlarged) time-temperature domain of the observations $(b)$ is marked by the colored circle (Color figure online).

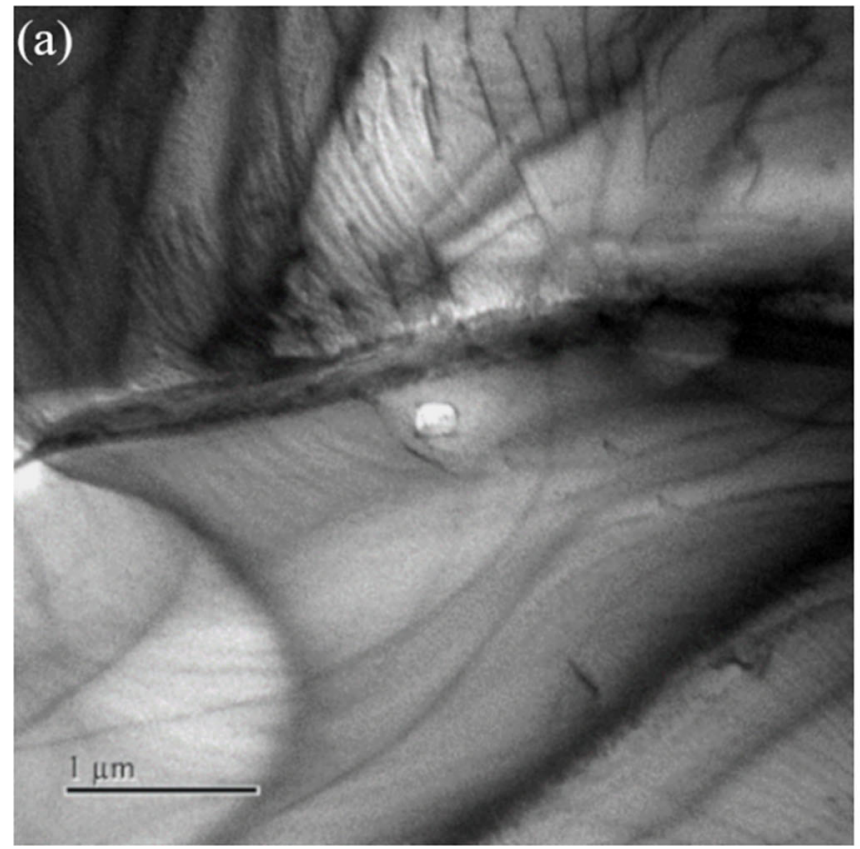

(b)

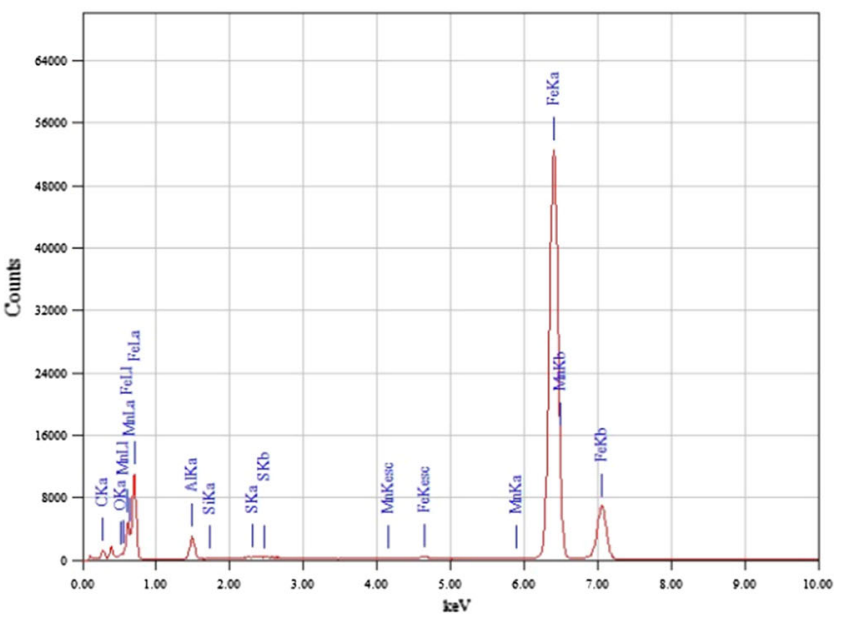

Fig. 2-(a) Bright field TEM of a particle found in the Fe-0.1C-1Mn steel after thermal cycling and (b) EDS spectra from the particle showing an $\mathrm{Al}$ peak.

this type, along with the associated TEM-EDS spectra indicating that the particle is likely to be an $\mathrm{Al}$ oxide particle with a diameter less than the local thickness of the foil. EELS thickness measurements, using a GATAN Quantum GIF with the F200 in STEM mode, were made on post-heat treatment thin foils indicating that the thickness in the areas under observation likely to be in excess of $300 \mathrm{~nm}$.

\section{RESULTS}

The observed pinning event reported here was recorded immediately after the first full $T_{1}-T_{2}-T_{1}$ cycle at the end of the austenite-to-ferrite transformation. The interaction of the interface with a particle with estimated dimensions of $140 \mathrm{~nm} \times 220 \mathrm{~nm}$ (normal and parallel, respectively, to the interface). There was a clearly apparent localized inhibition of the interface migration (up to $750 \mathrm{~nm}$ on either side of the pining particle) which 

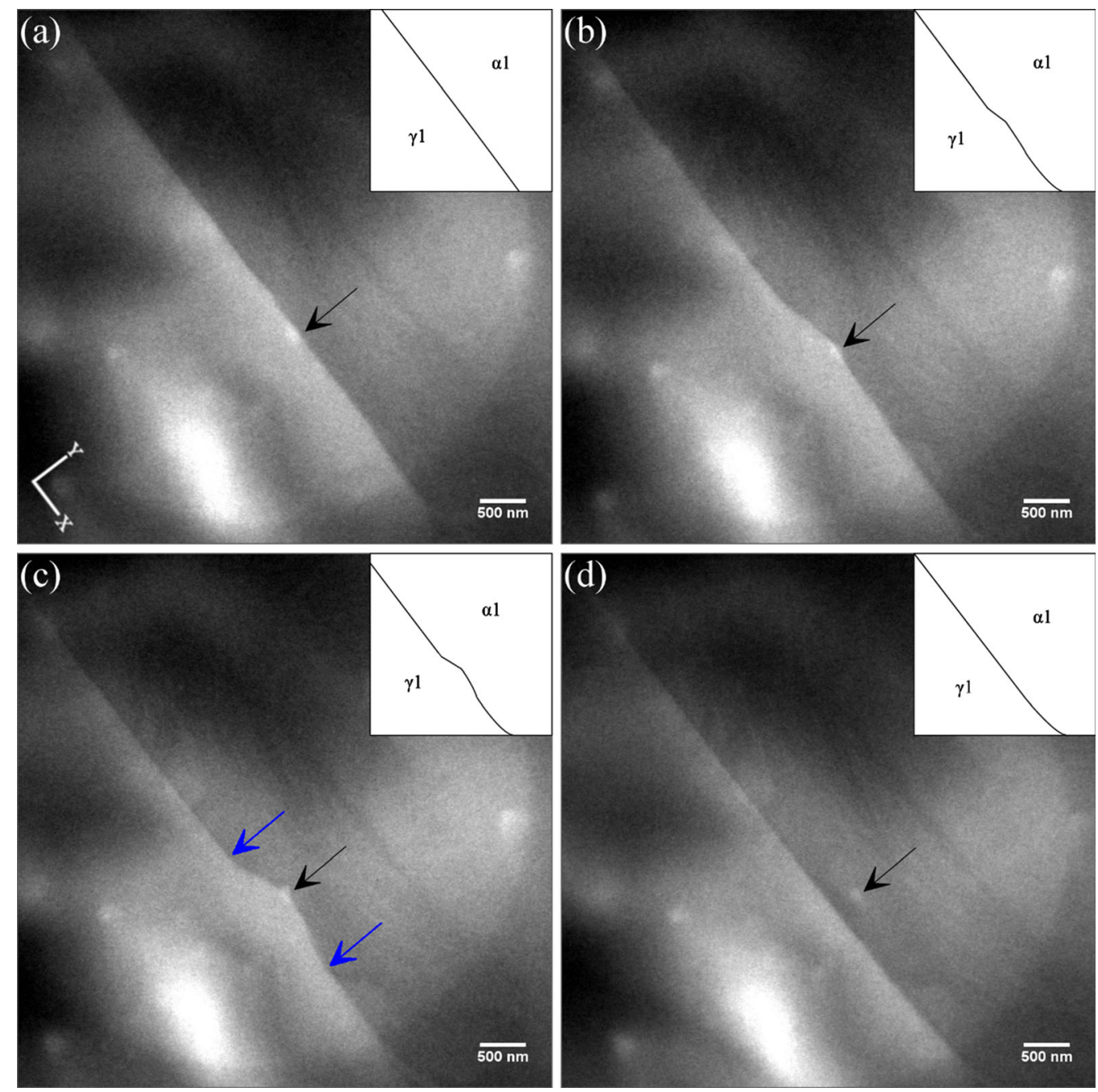

Fig. 3-Bright field TEM of the interaction of the interface with an unidentified particle $(a)$ at $1136.1 \mathrm{~s}\left(778{ }^{\circ} \mathrm{C}\right),(b)$ at $1141.4 \mathrm{~s}\left(779{ }^{\circ} \mathrm{C}\right),(c)$ at $1149.4 \mathrm{~s}\left(780^{\circ} \mathrm{C}\right)$ and $(d)$ at $1153.5 \mathrm{~s}\left(780^{\circ} \mathrm{C}\right)$. Black arrows indicate the particle, which is immobile between frames, the blue arrow indicates the reference point used for the measurements in Fig. 4. A full video of the observed pinning effect can be seen in supplementary video 1 (Color figure online).

developed over approximately 12 to 20 seconds. During this time the temperature nominally increased by $2.5^{\circ} \mathrm{C}$.

Figure 3 shows bright field TEM images of the interface immediately prior to, during and immediately after intersecting with the oxide particle. The migration of the interface was locally inhibited at the point of first contact with the particle, while the interface itself at either side of the particle continued to migrate in an unaffected manner. The developing perturbation extended to either side of the interface up to a well-defined distance, indicated in Figure 3 by the two blue arrows. As shown in Figure 3(c), the (maximal) pinning distance at the particle position was about 200 $\mathrm{nm}$, while the pining retardation extended over about $750 \mathrm{~nm}$ on either side of the particle, indicated by the blue arrows. Once the interface escaped from the pinning effect, the interface returned to a morphology comparable to that immediately before it came into contact with the particle (Figure 3(d)).
Even during the pinned period, it was possible to make an estimate of the position of the interface where it intersected the particle (as can be seen most clearly in 3(c)). This is due to the fact that the particle did not occupy the full thickness of the foil, and therefore in the TEM the section of interface above and below the foil could be seen. The migration distance from the estimated moment of first contact with the particle and the final frame in which a pinning effect could be seen was approximately $130 \mathrm{~nm}$, close to the estimated particle dimension in the migration direction.

Figure 4(a) summarizes how the interface moved during this interaction by plotting the interface position (perpendicular to the direction of motion) as a function of reduced time (the time of first physical contact between the interface and the particle is set to $t_{\text {red }}=0$ seconds) and reduced position ( $x=0$ is the position along the interface which impacts the center of the particle). In the plot, the interface position at $x=0$ (the impact point) and $x=+1000 \mathrm{~nm}$ (to the right of the particle) and $x=-1000 \mathrm{~nm}$ (to the left of the particle) 
is plotted. Both $x$ values were set to be about 33 pct larger than the maximum interaction distance [the distance between the blue and the black arrows in Figure 3(c)]. The figure shows that from $t_{\text {red }}=-10.4$ seconds to $t_{\text {red }}=0$ seconds, the interface migrates with a constant velocity, as would be expected from diffusion controlled growth at this stage of the austenite-to-ferrite transformation, and continues to do so once the pinning has come to an end $\left(t_{\text {red }}=+16.5\right.$ seconds to $t_{\text {red }}=$ +23.7 seconds). The interface position at $x=0 \mathrm{~nm}$ and $x= \pm 1000 \mathrm{~nm}$ correlates well during both of these periods.

Figure 4(b) shows the difference (in the y direction perpendicular to the moving interface) between the interface positions at $x=0$ and the average position at $x= \pm 1000 \mathrm{~nm}$ as a function of time and this most clearly reflects the pinning behavior. It shows that four distinct periods can be distinguished following the moment of first contact. In the first, for $t_{\text {red }}<0$, the interface migration at the point of intersection is inhibited, as can also be seen from Figure 3. From $t_{\text {red }}$ $=0$ to $t_{\text {red }}=16.2$ seconds, the interfacial velocity slows down, while the pinning force builds up. Finally, from $t_{\text {red }}=16.4$ seconds, the interface escaped from the influence of the second-phase particle, returning to an unperturbed position at $t_{\text {red }}=16.5$ seconds. The local austenite-ferrite interface velocity upon release of the particle was approximately 1700 pet higher than that of the unaffected interface. In the fourth and final period, all points along the interface migrate with a comparable velocity.

Finally, in Figure 4(c), we plot the length of the interface region affected by the pining particle (the distance between the 2 blue arrows) as a function of reduced time. The figure shows that the affected interface length rapidly increases to approximately $1400 \mathrm{~nm}$ and then slowly increases that length up to $1500 \mathrm{~nm}$ for 10 seconds before decreasing below 1300 $\mathrm{nm}$ prior to release. Initially, as far as the resolution of the TEM allowed, the interface was for the most part straight in between the fixed particle pinning point and the transient point at which the interface $(x-)$ position starts to deviate from its expected unaffected $(y-)$ position. Toward the end of the interaction, from about

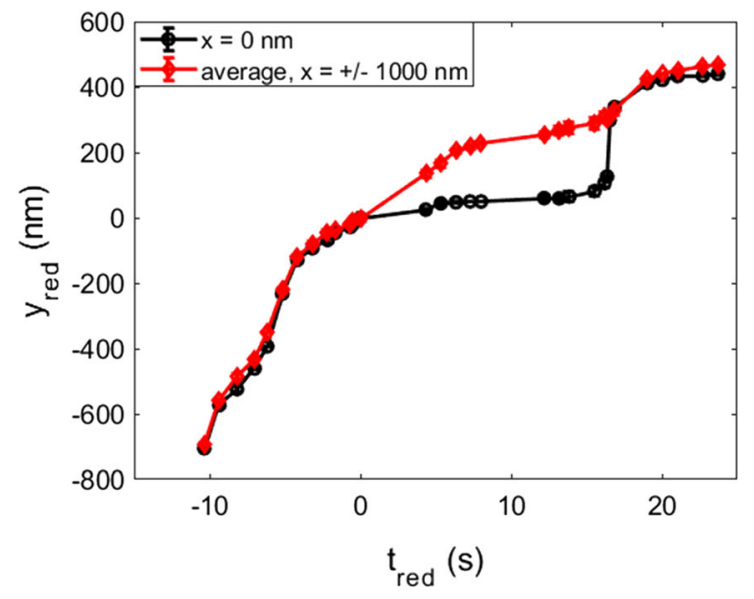

(a)

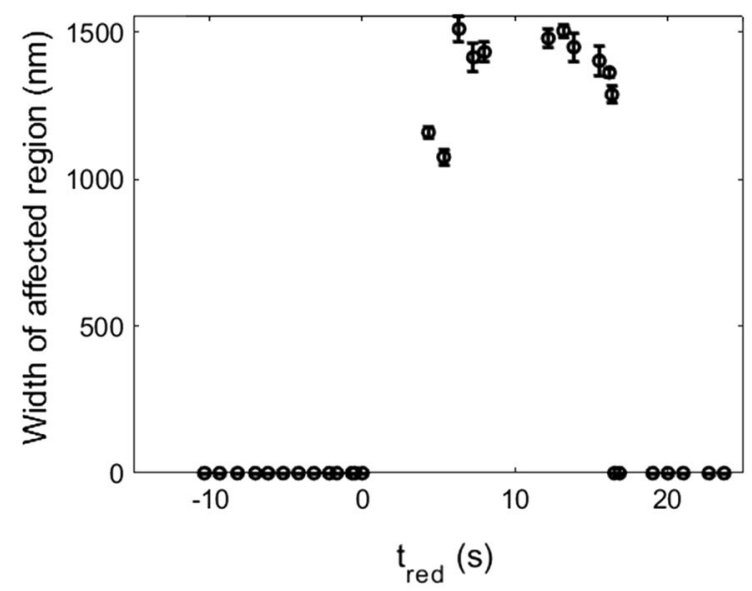

(c)

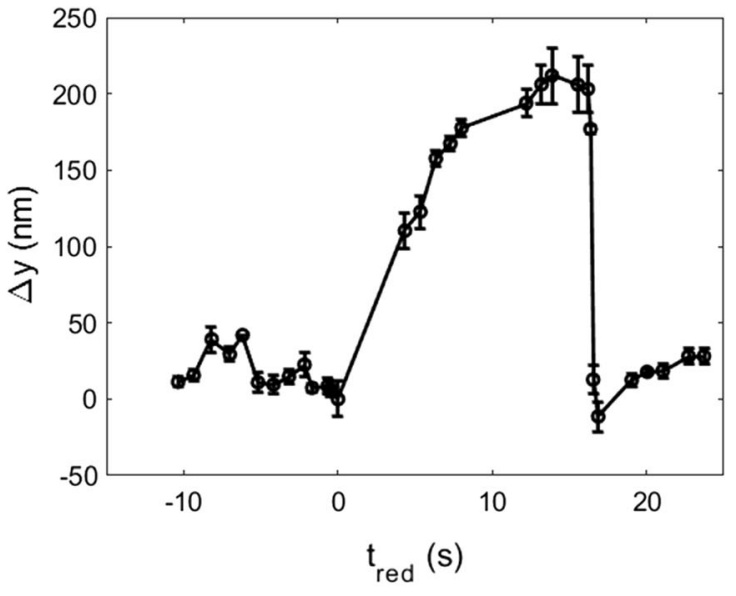

(b)

Fig. 4 - (a) Reduced interface position in the y direction against time for $x=0 \mathrm{~nm}$ (the position along the interface that intersects the particle) and the average of $x= \pm 1000 \mathrm{~nm},(b)$ the average difference in position in the $y$ direction at $x=0 \mathrm{~nm}$ and $x= \pm 1000 \mathrm{~nm}$ against time and (c) the width of the region showing a perturbation as a result of pinning against time. 
$t_{\text {red }}=12.2$ seconds, locally the interface became more noticeably curved. The average disinclination angle increased from $\theta=16 \mathrm{deg}$ at $t_{\text {red }}=4.3$ seconds to a maximum, measured between $t_{\mathrm{red}}=15.5$ and $t_{\mathrm{red}}=$ 16.2 seconds, of $\theta=30 \mathrm{deg}$.

There was some asymmetry in the behavior of the perturbed interface on each side of the particle, which is likely due to the not-fully-spherical nature of the particle. In general, however, the two sections of the interface behaved in a comparable manner over the course of the pinning effect, and after release the interface position at $x=0 \mathrm{~nm}$ correlated well with both $x=+1000 \mathrm{~nm}$ and $x=-1000 \mathrm{~nm}$, indicating that the driving force for the transformation did not differ significantly along the observed length of the interface.

Now we will proceed and compare the observations with existing particle-interface pinning models and derive quantitative values for the pinning force and the line tension involved in stretching the austenite-ferrite interface.

The line tension is defined as the increase in free energy associated with an increase in length. Here, it is calculated under the assumption that the area of the perturbation caused by the pinning effect, as seen in the TEM images, can be described by two right angled triangles. The depth of the perturbation in the $y$ direction [as in Figure 4(b)] meets the radius of the perturbation, $R$, at $90 \mathrm{deg}$ with $\theta$ as the adjacent angle to $R$.

Therefore, the unperturbed line tension, $S_{\mathrm{u}}$, is given in Eq. [1] and the perturbed line tension in Eq. [2] below:

$$
\begin{gathered}
S_{\mathrm{u}}=\gamma_{\mathrm{af}} \cdot R \\
S_{\mathrm{p}}=\gamma_{\mathrm{af}} \cdot R / \cos (\theta)
\end{gathered}
$$

where $\gamma$ is the austenite-ferrite interfacial energy, $R$ the radius of the perturbation and $\theta$ the adjacent angle.

Consequently, the increase in line tension as a result of the increased interface length caused by the perturbation can be calculated using Eq. [3]:

$$
\delta S=S_{\mathrm{p}}-S_{\mathrm{u}}=\gamma_{\mathrm{af}} \cdot R \cdot(\sec (\theta)-1)
$$

The pinning force, which is expected to be balanced by the line tension, was also estimated. In this case, the particle was assumed to be spherical and to have the same interfacial energy in both austenite and ferrite. $S$ was calculated for the interface on both sides of the particle and summed to calculate the total increase in line tension for the perturbation as a whole.

The pinning force, $F_{\mathrm{s}}$, exerted by a spherical particle is given using Eq. [4] ${ }^{[35]}$ below, with a maximum pinning force, $F_{\max }$, which occurs when $\theta=\pi / 4$ given in Eq. [5]:

$$
\begin{gathered}
F_{\mathrm{s}}=\gamma_{\mathrm{af}} \sin (\theta) \cdot 2 \pi r \cos (\theta) \\
F_{\max }=\pi r \gamma_{\mathrm{af}}
\end{gathered}
$$

where $r$ is the particle radius. $\gamma_{\text {af }}$ is the austenite-ferrite interface energy and $\theta$ is the angle of the interface where it intersects the particle.

The pinning force and line tension estimated from the TEM observations is shown in Figure 5 below. In both cases $\gamma_{\mathrm{af}}$ is assumed to be $0.8 \mathrm{~J} \mathrm{~m}^{-2}$. ${ }^{[36]}$ When the particle diameter is assumed to be $220 \mathrm{~nm}$ - the diameter of the particle parallel to the interface - the maximum pinning force calculated from Eq. [5] is $276 \mathrm{~nJ} \mathrm{~m}^{-1}$. For a particle with a diameter of $140 \mathrm{~nm}$ - the diameter of the particle normal to the interface - the maximum pinning force is $176 \mathrm{~nJ} \mathrm{~m} \mathrm{~m}^{-1}$.

For an elongated, ellipsoidal, particle where the ratio, $\varepsilon_{\mathrm{a}}$, of the diameter in the y direction against the diameter in the $x$ direction is great than 1 , then the pinning force per particle is given in Eqs. [6] and [7]. ${ }^{[37]}$

$$
\begin{gathered}
F_{x}=\frac{\pi d_{x} \gamma}{1+\varepsilon_{\mathrm{a}}} \\
F_{y}=\frac{\left(1+2.14 \varepsilon_{\mathrm{a}}\right) d_{x} \gamma}{2}
\end{gathered}
$$

where $F_{x}$ is the pinning force when the migration direction of the interface is parallel to the $y$ axis of the particle and $F_{y}$ is the pinning force when the migration direction is normal to the $y$ axis. $d_{x}$ is the particle diameter in the $x$ direction and $\gamma$ is the austenite-ferrite interface energy.

For the purposes of this calculation, $d_{x}$ is $140 \mathrm{~nm}, d_{y}$ is $220 \mathrm{~nm}$, the diameter of the particle normal to and parallel to the interface, respectively, and with $\gamma=$ $0.8 \mathrm{~J} \mathrm{~m}^{-2}$ as above. For $F_{x}$ (in this case, the direction parallel to the interface), the calculated maximum pinning force was $137 \mathrm{~nJ} \mathrm{~m}^{-1}$ and $F_{y}$ (the direction normal to the interface, and the migration direction) was $244 \mathrm{~nJ} \mathrm{~m} \mathrm{~m}^{-1}$. Consequently, it can be seen that if the particle deviates from a spherical to a more ellipsoidal geometry, the assumptions above will result in an overestimate of the pinning force.

Figure 5 shows that both the line tension and the pinning force increased in a comparable fashion from $t_{\text {red }}=+4.3$ seconds to $t_{\text {red }}=+16.2$ seconds before rapidly dropping off as the interface escaped from the

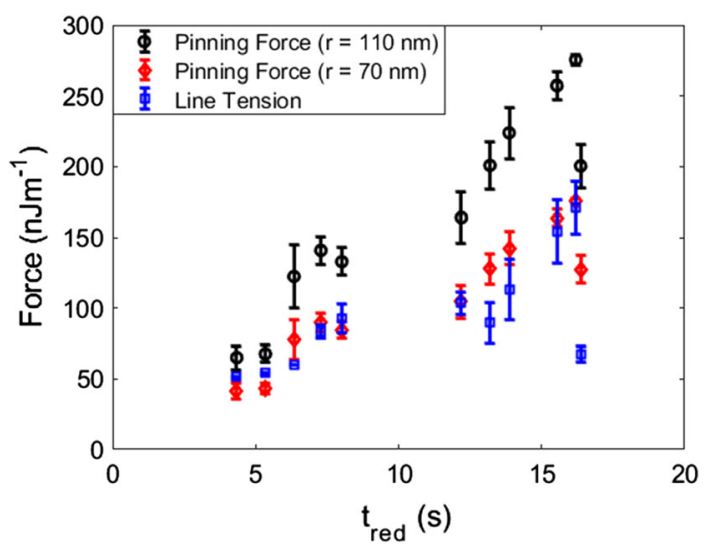

Fig. 5-Pinning force and the line tension versus the reduced time. 
pinning effect of the particle. The maximum pinning force, occurring at $t_{\text {red }}=+16.2$ seconds was 275 $\mathrm{nJ} \mathrm{m}{ }^{-1}$ when assuming $d=220 \mathrm{~nm}$ and $175 \mathrm{~nJ} \mathrm{~m}^{-1}$ for $d=140 \mathrm{~nm}$. The maximum line tension, occurring at the same time, was $170 \mathrm{n} \mathrm{m}^{-1}$.

\section{DISCUSSION}

Qualitatively, the interfacial behavior developed as expected from classical descriptions of a migrating interface pinned by a single particle. ${ }^{[12]}$ The migration of the interface was inhibited around the particle leading to a growing perturbation on either side, with a build-up of the contact angle, to approximately $45 \mathrm{deg}$, before the relatively rapid release of the interface. From Figure 4(a), it can be seen that during this period, the migration of the interface was reduced, and that after the interface had been released the local migration rate increased sharply -indicating that the particle had an overall constraining effect on the motion of the interface, before dropping to the undisturbed value. Although the austenite-ferrite interface does not appear to display the expected 3-dimensional catenoid shape ${ }^{[35,38]}$ which could be attributed to the specimen dimensions, it should be noted that the behavior differs from that suggested by Hillert ${ }^{[38]}$ for a 2-dimensional system where unpinning only takes place when the two sides of the boundary meet behind the particle (that is, when the entire grain is about to disappear).

The calculated values for the pinning force and the line tension both show an increase between $t_{\text {red }}=4.3$ seconds and $t_{\text {red }}=16.2$, reaching a peak at $275 \mathrm{~nJ} \mathrm{~m}^{-1}$, $175 \mathrm{~nJ} \mathrm{~m}^{-1}$, and $170 \mathrm{~nJ} \mathrm{~m}^{-1}$ for a particle with a $110 \mathrm{~nm}$ radius, a $70 \mathrm{~nm}$ radius and the line tension, respectively. In general, there is very good agreement, particularly at the maximum values, between the line tension and the pinning force for a particle with a $70 \mathrm{~nm}$ radius.

From Figure 4(c), it can be seen that the length of the affected area rapidly widened to approximately $1400 \mathrm{~nm}$ and maintained and increasing more modestly over the subsequent 10 seconds. At the end of the period of interaction there was an appreciable decrease in the length. From Figure 5, it can be seen that the line tension displayed comparable behavior.

As with the increase in width, the line tension began to increase at a decreased rate after approximately $t_{\text {red }}$ $=8.0$ seconds. Taken with the position measurements in Figures 4(a) and 4(b) this also indicates that there was a general reduction in the interface velocity at $t_{\text {red }}=8.0$ seconds. The temperature at this time was $780{ }^{\circ} \mathrm{C}$, which is approximately the estimated start time of the stagnant stage in a $\mathrm{Fe}-0.1 \mathrm{C}-1.0 \mathrm{Mn}$ steel undergoing the imposed CPPT heat treatment. ${ }^{[39]}$ Consequently, this represents a general slowing of the transformation kinetics as a result of the changing driving force for the transformation rather than one brought about by some effect of interface-particle interaction.

The visible part of the interface was predominantly straight during the interface-particle interaction, facilitating the analysis of the resulting perturbation.
Previous in situ TEM studies of the austenite-to-ferrite transformation $^{[28,31]}$ showed that during the normal transformation, there can be local variations in the morphology of the interface varying between curved and nearly straight. During the stagnant stage, which has been attributed to a significant interfacial enrichment of $\mathrm{Mn},{ }^{[33,34]}$ the interface was observed to maintain a more consistently straight morphology like that seen in the present experiments. ${ }^{[31]}$

2D phase field simulations of the $\delta$-ferrite-to-austenite transformation by Sato et al. ${ }^{[4]}$ provide a useful point of comparison with the present study. While there are some differences, there is qualitative agreement between the observed behavior and the simulated behavior as the pinning effect developed. In particular, Figure 4(b) from $t_{\text {red }}=0$ to $t_{\text {red }}=16.2$ shows an increasing position difference between the pinned and unpinned parts of the interface, followed by a relatively rapid convergence of the two sections on release.

Zhou et al. ${ }^{[40]}$ performed molecular dynamics simulations of a particle-grain boundary interaction for a $\mathrm{Cu}$ bi-crystal and performed direct measurements of the pinning force. The estimated grain boundary energy ranges from 0.87 to $0.93 \mathrm{Jm}^{-2}$ depending on misorientation-which is close to the interface energy assumed for the austenite-ferrite interface above. The development of the boundary shape observed here for a ferrite-austenite interface in a model alloy for a low alloyed steel agreed well with that calculated for the grain boundary in a pure $\mathrm{Cu}$ bi-crystal.

\section{CONCLUSION}

Direct TEM observations of the interaction between an oxide particle and a migrating austenite-ferrite interface displayed the expected features of Zener pinning including the localized inhibition of migration at the particle, a reduction in the overall migration velocity for the interface as a whole and a build-up of the pinning force until the interface was released. Further, the results show qualitative agreement with the most comparable simulations found in the literature. A very good agreement between the pinning force $(175$ $\left.\mathrm{nJ} \mathrm{m}{ }^{-1}\right)$ and the interface line tension $\left(170 \mathrm{~nJ} \mathrm{~m}{ }^{-1}\right)$ is obtained.

\section{ACKNOWLEDGMENTS}

This work was supported by the Engineering and Physical Sciences Research Council (EPSRC) through the Centre for Doctoral Training in Advanced Metallic Systems (EP/G036950/1). We wish to acknowledge the Henry Royce Institute for Advanced Materials, funded through EPSRC Grants EP/R00661X/1, EP/ S019367/1, EP/P02470X/1 and EP/P025285/1, for the financial support and JEOL JEM-F200 access at Royce@Sheffield. 


\section{OPEN ACCESS}

This article is licensed under a Creative Commons Attribution 4.0 International License, which permits use, sharing, adaptation, distribution and reproduction in any medium or format, as long as you give appropriate credit to the original author(s) and the source, provide a link to the Creative Commons licence, and indicate if changes were made. The images or other third party material in this article are included in the article's Creative Commons licence, unless indicated otherwise in a credit line to the material. If material is not included in the article's Creative Commons licence and your intended use is not permitted by statutory regulation or exceeds the permitted use, you will need to obtain permission directly from the copyright holder. To view a copy of this licence, visit http://creat ivecommons.org/licenses/by/4.0/.

\section{ELECTRONIC SUPPLEMENTARY MATERIAL}

The online version of this article (https://doi.org/10. 1007/s11661-020-05824-y) contains supplementary material, which is available to authorized users.

\section{REFERENCES}

1. P.A. Manohar, M. Ferry, and T. Chandra: ISIJ Int., 1998, vol. 38, pp. 913-24.

2. S. Kencana, M. Ohno, K. Matsuura, and K. Isobe: ISIJ Int., 2012, vol. 50, pp. 1965-71.

3. T. Garcin, K. Ueds, and M. Militzer: Metall. Mater. Trans. A, 2017, vol. 48A, pp. 796-808.

4. D. Sato, M. Ohno, and K. Matsuura: Comp. Mater. Sci., 2015, vol. 106, pp. 88-192.

5. B. Dutta and C.M. Sellars: Mater. Sci. Tech., 1986, vol. 2, pp. $146-53$.

6. S. Vervynckt, K. Verbeken, P. Thibaux, and Y. Houbaert: Mater. Sci. Eng. A, 2011, vol. 528, pp. 5519-28.

7. D. San Martín, F. G. Caballero, C. Capdevila and C. García de Andrés: Mater. Trans., 2004, Vol. 45 pp. 2797-2804.

8. P.A. Manohar, D.P. Dunne, T. Chandra, and C.R. Killmore: ISIJ Int., 1996, vol. 36, pp. 194-200.

9. S.F. Medine, A. Quispe, P. Walles, and J.L. Baños: ISIJ Int., 1999, vol. 39, pp. 913-22.

10. C.S. Smith: Trans. Metall. Soc. A.I.M.E., 1948, vol. 175, pp. $15-51$.

11. P. Cotterill and P.R. Mould: Recrystallization and Grain Growth in Metals, Surrey University Press, London, 1976, pp. 233-35.
12. E. Nes, N. Ryum, and O. Hunderi: Acta Metall., 1985, vol. 33, pp. 11-22.

13. H. Dong, H. Chen, W. Wang, Y. Zhang, G. Miyamoto, T. Furuhara, C. Zhang, Z. Yang, and S. van der Zwaag: Acta Mater., 2018, vol. 158, pp. 167-79.

14. L. Chen, K. Matsuura, D. Sato, and M. Ohno: ISIJ Int., 2012, vol. 52 , pp. 434- 40 .

15. L. Chen, K. Matsuura, M. Ohno, and D. Sato: ISIJ Int., 2012, vol. 52, pp. 1841-47.

16. S. Morioka and H. Suito: ISIJ Int., 2008, vol. 48, pp. 386-293.

17. X. Mao, K.H. Oh, and J. Jang: Mater. Charact., 2016, vol. 117, pp. 91-98.

18. D. Sato, M. Ohno, and K. Matsuura: Metall. Mater. Trans. A, 2014, vol. 46, pp. 981-88.

19. R. Elst, J. van Humbeeck, and L. Delaey: Acta Metall., 1988, vol. 36, pp. 1723-29.

20. N.A. Haroun and D.W. Budworth: J. Mater. Sci., 1968, vol. 3, pp. $326-28$.

21. N. Moelans, B. Blanpain, and P. Wollants: Acta Mater., 2005, vol. 53, pp. 1771-81.

22. A.C.F. Cocks and S.P.A. Gill: Acta Mater., 1996, vol. 44, pp. 4765-75.

23. M. Guo and H. Suito: ISIJ Int., 1999, vol. 39, pp. 1289-96.

24. N. Want, Y. Wen, and L.-Q. Chen: Comp. Mater. Sci., 2014, vol. 93 , pp. 81-85.

25. T. Gladman, G. Fourlaris, and M. Talafi-Noghani: Mater. Sci. Tech., 1999, vol. 15, pp. 1414-24.

26. H.P. Longworth and C.V. Thompson: J. Appl. Phys., 1991, vol. 69 , pp. $3929-40$.

27. G.R. Purdy: Acta Metall., 1978, vol. 26, pp. 477-86.

28. M. Onink, F.D. Tichelaar, C.M. Brakman, E.J. Mittemeijer, and S. van der Zwaag: J. Mater. Sci., 1995, vol. 30, pp. 6223-34.

29. J. Du, F. Mompiou, and W.-Z. Zhang: Scr. Mater., 2018, vol. 145, pp. 62-66.

30. F. Mompiou, J. Wu, and W.-Z. Zhang: Mater. Today, 2015, vol. 2 S, pp. S651-54.

31. J. Nutter, H. Farahani, W.M. Rainforth, and S. van der Zwaag: Acta Mater., 2019, vol. 178, pp. 68-78.

32. H. Chen and S. van der Zwaag: Metall. and Mater. Trans. A, 2017, vol. 48 , pp. $2720-29$.

33. H. Chen and S. van der Zwaag: Comp. Mater. Sci., 2010, vol. 49, pp. 801-13.

34. H. Chen, B. Appolaire, and S. van der Zwaag: Acta Mater., 2011, vol. 59, pp. 6751-60.

35. A. Harun, E.A. Holm, M.P. Clode, and M.A. Miodownik: Acta Mater., 2006, vol. 54, pp. 3261-73.

36. Z. Yang and R.A. Johnson: Model. Simul. Mater. Sci. Eng., 1993, vol. 1, pp. 707-16.

37. N. Ryum, O. Hunderi, and E. Nes: Scr. Metall., 1983, vol. 17, pp. 1281-83.

38. M. Hillert: Acta Metall., 1988, vol. 36, pp. 64-3181.

39. J. Nutter: Direct TEM Observation of the Movement of the Austenite-Ferrite Interface in Steels, PhD Thesis, University of Sheffield, 2018, pp. 147-71.

40. J. Zhou, W. Li, B. Zhao, and F. Ren: Acta Mater., 2018, vol. 148, pp. $1-8$.

Publisher's Note Springer Nature remains neutral with regard to jurisdictional claims in published maps and institutional affiliations. 